\title{
The strategy and tactics of cases in marketing education
}

\author{
Ross Brennan \\ Principal Lecturer in Marketing \\ Middlesex University Business School \\ The Burroughs \\ Hendon \\ London \\ NW4 4BT \\ r.brennan@mdx.ac.uk
}

\author{
Michael John Harker ${ }^{1}$ \\ Lecturer in Marketing \\ Department of Marketing \\ University of Strathclyde \\ 173 Cathedral St \\ Glasgow \\ G4 ORQ \\ michael.harker@strath.ac.uk
}

\begin{abstract}
:
To what degree have you considered your use of cases within your teaching? This paper suggests more and better planning and organisation at all levels from the individual and tactical through to the programme, group and academy is required if the method is to be used more effectively. It contains suggestions and criteria by which such planning and decision making could be carried out, before reflecting on the value possible in producing case studies as a useful by-product of research projects large and small.
\end{abstract}

\section{Context}

"At undergraduate, postgraduate and practitioner level, the case study is a well-accepted and widely used learning tool. The established popularity of case studies in marketing management education is primarily linked to the technique's ability to bridge the gap between marketing theory and practical situations. This capacity to make the connection between standard textbooks and real business problems allows students to practise applying the theoretical concepts they have learnt. This is achieved by providing students with appropriate background and market information, then asking them to take responsibility for making key marketing decisions. ” Dibb and Simkin (1994:11)

To expand a little, the orthodox view of case studies is that they are a useful, possibly an indispensable component of a managerially-orientated marketing education. The success of a marketing education depends, it is implicitly assumed, upon how well students are prepared to enter graduate marketing jobs. Therefore, in order to achieve this, bridges must be built between the "less real" worlds of the classroom and marketing theory, and the "more real" world of marketing practice. That case studies are an excellent piece of bridgebuilding equipment with which students can engage with the type of problems that face marketing managers, can explore and develop solutions, can put into practice analytical techniques, can engage in constructive debate about alternative courses of action, and can do all of this without endangering the economic success of any real business is widely accepted. Furthermore, a range of generic business skills, such as working in teams, making presentations and writing reports can be practised using the medium of the case study. Some equally important but less clearly defined learning goals may also be achieved through the use of the case method. Since there is usually no clear-cut "right" answer to a case study, students may be prepared for the ambiguous, shades-of-grey managerial reality for which they are presumed to be destined. Case studies may be written to contain a superfluity of irrelevant information, and to lack certain key pieces of information; again, the presumption is that the ability to sort good information from bad, and to exercise good judgement when one lacks crucial information, are excellent preparation for work in marketing management.

\footnotetext{
${ }^{1}$ Address for correspondence
} 
Furthermore, and here is perhaps the clincher for anyone sceptical about the use of case studies in marketing education, the educational approach at the Harvard Business School - by some margin the biggest brand in management education - is built around the case study method. The orthodoxy thus described is essentially a pragmatic one. Clearly the case study method remains hugely popular in marketing education (witness the liberal sprinkling of case studies in any textbook of marketing). Our purpose with paper therefore is to consider how cases might be used more effectively in marketing education by considering their use tactically - within a specific class and even session but also strategically - at a programme or other macro-level across classes, topics and educational objectives.

\section{The tactics of using cases in marketing education}

Let us first consider the opinion of those for whom cases are selected and integrated - successfully, thoughtfully or otherwise - into a marketing class. Whilst reservations have been expressed, generally speaking students on marketing and strategy courses, when you ask them, tend towards the opinion that the use of case studies helps them to learn valuable analytical and communications skills, and to bring the real world of business into the classroom. There is some evidence that there are important differences between different categories of student in terms of attitudes towards case studies - for example, between students with different types of entry qualifications, between more and less mature students, and between students from different ethnic backgrounds (Brennan \& Ahmad 2005). But in general case studies are a learning approach that is fairly well-liked by students, and one which they think is effective.

Regrettably, few marketing educators have given much thought to any underlying theory of learning that might justify the use of the case study method (for anyone interested in investigating the subject, Mumford (2005) provides a few pointers) in their own teaching or of the teaching of programmes with which they are connected. The esteemed psychologist and learning theorist Chris Argyris (1980) studied the Harvard case study method in action and found that the implementation of the method was substantially at odds with the "espoused theory" of the faculty members involved (for example, professors asserted that there were no right or wrong answers, but then guided the case study discussion in the direction of a solution that they clearly seemed to prefer). It seems worthwhile then to consider the tactical situation - what factors and issues should impact upon the selection of a case?

We suggest that there are four key elements to consider:

1. Characteristics of the students

2. The focus and objectives of the class

3. Characteristics of the case

4. Characteristics of the educator

Let us take each of these in turn. Students of marketing are a varied bunch. How do they vary? Demographically they might be a group of young people from a similar background or a real mix of ages especially on a part-time or professionally orientated class. Personal experience suggests that there is a slight imbalance in favour of women. Ethnicity and social background can be enormously varied as in many metropolitan institutions - or be limited to a relatively narrow range, Strathclyde draws three-quarters of its Business School intake from the south-west of Scotland and it may interest readers to know that it is usual to have more Scandinavians than English students in any given class. Educationally and in terms of experience the variance might be enormous. On an undergraduate programme, it is likely that any previous encounter with marketing issues would be limited in scope and scale. We might also consider the regrettable level of innumeracy amongst business school undergraduates. On an 'executive MBA' each learner might have the facility to draw on decades of significant experience in a range of positions and industries.

What implications might these factors have on selection of a case? Even final year undergraduates in marketing are often relatively unfamiliar with certain aspects of marketing - especially those involving planning and measuring. The tutor selecting a case study on mobile phone retailing is a brave soul who needs 
to ensure that the case study reflects the most recent developments in the market, or run the risk that the classroom session will descend into a lengthy critique of the case study itself. The tutor selecting a case study on the industrial selling process in heavy construction, for an undergraduate class, has rather different selection criteria; perhaps most important is that the case study should clearly illuminate the basic processes of business-to-business buying and selling for the students.

The focus and characteristics of the class being taught also affect the selection of appropriate case studies. To some extent this overlaps with the prior experience and education of the students. Generally, as one moves through the levels of higher education from undergraduate to postgraduate to post-experience, one can also expect to encounter more experienced students. In some relevant respects the many overseas students who are found on postgraduate courses may be considered "less experienced"; indeed, such students may well present particular challenges to the tutor when selecting appropriate case studies, if their cognitive development is of a high order, while their grasp of the background context to the case studies used is fairly limited. In addition to the academic level of the course, one should consider the related issues of subject matter and degree of managerial orientation when selecting teaching case studies. It is a reasonable assumption that the majority of marketing education in North America and Europe has a managerial orientation. However, non-managerial approaches to marketing education are also to be found, including macromarketing and critical marketing theory. Should the tutor who intends to deliver a macromarketing or critical marketing course foreswear case studies? It is not obvious that there is anything intrinsic to the case study teaching method that makes it unsuitable for non-managerial courses. The difficulty, of course, is that the great majority of marketing case studies have been developed using a managerial perspective. In principle at least, the use of case studies in macromarketing courses (for example, historical case studies to illustrate comparative marketing systems, and case studies in marketing ethics) and critical marketing (for example, case studies illuminating feminist or Marxist critiques of marketing orthodoxy) seems feasible.

Turning now to the characteristics of the case studies themselves. The nature and structure of cases is nearly as diverse as the order coleopteran. Nevertheless, we recognise them when we see them. What is the nature of the variety? Setting aside such basics as language - and it seems safe to assume the vast majority of cases are written [and learned?] in English and length/detail - it is also worth considering content. Narrative text or formal report? Primary and/or secondary data - numbers or words or images? Does the case implicitly ask for decisions or plans? Does it develop understanding of concepts or processes? Perhaps it allows the application of skills and knowledge? Any case study is a combination of the real and the hypothetical. Some are clearly closer to a description of reality than others. However, even a "made-up" case study must be based on some life experience of the author, while the most "real" of case studies must clearly be written from a particular perspective. No doubt the "reality" of the organisation would look different from other perspectives.

And what of the educator? Is there personal experience of the context of case from prior or current research or employment? Can all aspects and content of the case - e.g. numerical data - be properly commented upon? If the case must be credible, so must the tutor it is supporting.

\section{The strategy of cases in marketing education}

The previous sections have considered aspects of use in tactical situations - one or a few educators selecting a case or cases for a specific group of students in a specific class. Whilst this process of selection and use of cases is less explicit and planned than is perhaps ideal, disasters are thankfully rare - instinct and malleability usually allow at least a partial success at the tactical level. However, at the strategic level the use of cases in marketing education is much less accomplished.

In considering strategic issues we suggest that there are levels - programme team, academic group, business school and academy - and that for each of those it is worth considering not just the ways and means of caseconsumption, but also of case production. Further, we suggest that better planning and exploitation at each of these levels would result in better outcomes for all involved. 
Let us begin by imagining a teaching team. Our tactical portion considered individual case selection and suggested criteria and guidelines, but what else must be done at the first step-back from the front line? To judge each case individually in the context of the class and students is one thing - but what of considering a set of cases to be used over the course of the class? Is their harmony and synergy in the set? What is meant by this? Are concepts and ideas introduced in cases in early sessions required to be applied in those towards the end? Is a different issue within a similar industry examined by each case in the set? Perhaps the same issue across several sectors? At the level of programme is there any direction and control over the use of cases? Certainly individual colleagues must have tactical control, but are checks in place to make sure duplication and repetition is avoided and that programme themes [e.g. 'international marketing'] are reflected strongly by case-choice?

At the level of the academic group similar issues exist - the 'mix and match' nature of many programmes and the complexity of departmental teaching portfolios means that as with knowledge and skills and assessments, there is a need for group-wide planning. One criticism of business research is that each strand - marketing, HR, management, entrepreneurship etc - operates within its own silo. This seems to also be true for teaching on business programmes within which students have classes across several strands. Outwith the scope of this paper is consideration of the argument that integration between strands at a business school is risible at best and absent at worst and that the extreme specialisation of most business school academics makes them unable - even if willing - to integrate other strands into their teaching. This lack of integration surely reduces the overall effectiveness of business education. If cases are useful for the real world situations they present, then surely cases which incorporate more than one strand - e.g. marketing and HR - would better resemble managerial reality and would therefore be a step towards better integration?

This brings us onto our other strategic perspective - case production. At each of these levels, to what extent will case-materials be produced internally or sourced externally?

Young colleagues, serving their tutor/researcher apprenticeship are under pressure to produce significant publications even before they submit a thesis. Whilst not wishing to argue that the production of a good quality case study would be preferable to a formal journal article, it can be argued that it is a piece of writing that could be done early on in a doctoral research project and could be an efficiently produced by-product of collecting secondary data and a set of investigative relationships in preparation for forming research questions. Additionally, it would be a thesis-topic related paper and a case on a fresh, up-to-date topic almost certainly of genuine use to others. It might also be said, given the relative simplicity of writing a case compared to other forms of output that if that was beyond the researcher then it is a clear sign that the larger project is perhaps inadvisable. This task could be made less intimidating by working with a supervisor or doctoral programme manager.

Individually or collectively, academics have defined and specific research projects. As with our apprentices, there is a requirement to publish-or-perish, especially when external sources of funding have been obtained. The primary objective - as with $\mathrm{PhD}$ students - is one or more publications in appropriate journals. That being said, it seems certain that any project of this nature would have stories appropriate for conversion into a case. The statistics on reader-numbers for a typical paper being what they are, a case-paper might be a useful means of dissemination and of incorporating leading-edge research into teaching. It would also be intelligible to groups outside the academic community - government agencies and media spring to mind.

At the group and school level, it seems obvious that more could be done to encourage the development of a local case library to supplement any resources bought in. Not only is there a cost saving - and the ECCH model allows it to be revenue generating for a contributing group - it would also be a method of strengthening identity and rebalancing topics towards local specialities and needs. At the level of the academy, work needs to be done to identify areas of over-supply [fashionable or easily interesting topics] and under-supply [unfashionable and hard topics] and corrective action taken - perhaps even the development of a case-library. Better recognition of cases as a valid and parallel stream of output to conventional articles would also be of great help. 


\section{Conclusion}

The goal of this short article has been to encourage marketing educators - individually and collectively - to think about the 'how and why' of case studies on their courses - to make informed and deliberate choices rather than guesses. We hope that this paper will generate further discussion and better planning and organisation. Case studies should be used because they are considered to be an effective method of promoting student learning, not because "that's the way we have always done it", or "that's the way it's done everywhere else". Rather, explicit thought and planning is required.

\section{References}

Argyris, C. (1980), "Some Limitations of the Case Method: Experiences in a Management Development Program", Academy of Management Review, 5(2): 291-298

Brennan, R. \& Ahmad, J. (2005), "Using Case Studies in Management Education: The Student Perspective", International Journal of Management Education, 4(3): 21-30

Dibb, S. \& Simkin, L. (1994), The Marketing Casebook: Cases and Concepts, London: Routledge

Klebba, J. M. \& Hamilton, J.G. (2007). "Structured Case Analysis: Developing Critical Thinking Skills in a Marketing Case Course" Journal of Marketing Education, 29(2), 132-137,139

Mumford, A. (2005), “The Case Method - Does Learning Theory Matter?", Development and Learning in Organizations, 19(4): 17-19 